\title{
Analytical Tools and Strategic Approach to Detect Poor Quality Medicines, Identify Unknown Components, and Timely Alerts for Appropriate Measures: Case Study of Antimalarial Medicines
}

\author{
Védaste Habyalimana ${ }^{1,2}$, Jérémie Kindenge Mbinze ${ }^{1,3}$, Nicodème Kalenda Tshilombo1,3, \\ Amandine Dispas' ${ }^{1}$, Achille Yemoa Loconon ${ }^{1,4}$, Pierre-Yves Sacré1, Joëlle Widart5, \\ Pascal De Tullio ${ }^{6}$, Stéphane Counerotte ${ }^{6}$, Justin-Léonard Kadima Ntokamunda ${ }^{7}$, \\ Eric Ziemons $^{1}$, Philippe Hubert ${ }^{1}$, Roland Marini Djang' eing'a ${ }^{1}$ \\ ${ }^{1}$ Department of Pharmacy, CIRM, Laboratory of Analytical Chemistry, Quartier Hôpital, University of Liege (ULg), \\ Liège, Belgium \\ ${ }^{2}$ Rwanda Biomedical Center/Medical Procurement and Production Division, Butare, Rwanda \\ ${ }^{3}$ Faculté des Sciences Pharmaceutiques, Université de Kinshasa, Kinshasa XI, République Démocratique du \\ Congo \\ ${ }^{4}$ Ecole de Pharmacie, Faculté des Sciences de la Santé, Université d’Abomey Calavi, Cotonou, Bénin \\ ${ }^{5}$ Department of Pharmacy, CIRM, Quartier Hôpital, University of Liege (ULg), Liège, Belgium \\ ${ }^{6}$ Department of Pharmacy, CIRM, Laboratory of Medicinal Chemistry, Quartier Hôpital, University of Liege \\ (ULg), Liège, Belgium \\ ${ }^{7}$ School of Medicine and Pharmacy, University of Rwanda, Butare, Rwanda \\ Email: rmarini@ulg.ac.be
}

Received 19 September 2015; accepted 29 November 2015; published 2 December 2015

Copyright (C) 2015 by authors and Scientific Research Publishing Inc.

This work is licensed under the Creative Commons Attribution International License (CC BY). http://creativecommons.org/licenses/by/4.0/

(c)

\section{Abstract}

Nowadays, the circulation of poor quality medicines is becoming an alarming worldwide phenomenon with serious public health and socio-economic concerns. The situation is particularly critical in developing countries where drug quality assurance and regulatory systems for drug manufacturing, importation, distribution and sales are weak. A sustained vigilance on poor quality medicines that regroup counterfeit/falsified, substandard and degraded medicines is therefore required to ensure patient safety and genuine medicines integrity. A case situation is illustrated including a strategic approach and analytical tools that were found useful to detect poor quality me- 
dicines, identify unknown components, and timely alerts for appropriate measures against the spread of those harmful products. Several suspected medicines randomly sampled in several strategic Rwandan areas were firstly check-controlled by means of visual inspection and then applying several analytical techniques from simple to more complex ones. The following medicines were studied: quinine sulfate tablets, artemisinin-based combination tablets, and artesunate powders for injection. Taking into account the pharmaceutical forms and the chemical characteristics, the following tests were applied: uniformity of mass, friability, disintegration, fluorescence, identification and assay. They were followed by more complex analytical techniques that allowed more comprehension of abnormal findings among which the presence of a wrong active pharmaceutical ingredient in quinine sulfate tablets which is mainly discussed in this paper to illustrate a strategic approach and various analytical tools that can be used in detecting and identifying unknown component in poor quality medicines.

\section{Keywords}

Poor Quality Medicines, Antimalarial Medicines, Visual Inspection, Simple and Complex Analytical Tools

\section{Introduction}

Over the past several years, the health of human beings is threatened not only by the old and new diseases, but also by the consumption of medicines that are not well known and mostly of poor quality. Today, more people than ever put their health in danger by purchasing and consuming medicines of doubtful quality. For example, up to $10 \%$ of all medicines sold worldwide are estimated to be counterfeit and in some parts of Africa and Asia the prevalence exceeds 30\% as mapped in 2008 by Sonafi-Aventis [1]. The extent of damages caused by such drugs requires high collaborative endeavors at national and international levels to securize the public health, but also the trade of genuine products which are targeted by counterfeiters and deliberately falsified. Counterfeiters have gained access to sophisticated technologies that enable them to very closely imitate the packaging and labeling of legitimate generic or brand products [2]-[4]. However, in certain cases these products may contain unexpected products such as toxic ingredients, be ineffective or cause adverse effects due to incorrect concentration of the active ingredients or to the presence of wrong ones. In some circumstances, a drug that was initially of good quality may lose it for example by decrease of its potency or becoming toxic due to inappropriate storage conditions that lead to the appearance of impurities or degraded products. Newton et al. [5] distinguished three categories of poor quality medicines: 1) Counterfeit/falsified medicines which are illicit products maliciously produced and distributed; 2) Substandard also called out-of-specification "OOS" products which are genuine products generally produced in poor manufacturing conditions; and 3) Degraded medicines which are products improperly stored, and spoiled.

Detecting counterfeit or falsified medicines is a big challenge for healthcare professionals in charge of drug quality control. Strategies and specifications have been set up by several international organizations such as FDA, WHO, and EMA, defining requirements and procedures to follow for drug quality assessment. The first step to detect poor quality is usually the "visual inspection" on the physical characteristics of packaging, outer containers' labeling, closures, sealing, as well as the appearance of a medicine itself by its color, smell, consistency, etc. [2] [6]. Inspection of the storage conditions at the sampling sites such as the temperature, humidity, and exposure to light, is also one of the strategies recommended. During visual inspection, critical alterations are easily detected. Spoiled tablets, oral suspensions that harden, fluids leaking or containing particles/molds are quite enough signs to decide the non-conformity of a product without undergoing further laboratory tests. Nevertheless, this inspection needs a minimum and informative training to medicines end users for them to detect poor quality suspicions or visual evidences. Furthermore, laboratory analysis is of paramount importance during drug quality control for accurate identification and/or quantification of the active ingredients, and whenever possible of the excipients or impurities. That may necessitate using simple analytical techniques such as colorimetric tests, thin layer chromatography (TLC), UV-Vis spectroscopy or more complex techniques such as gas 
chromatography (GC), high performance liquid chromatography (HPLC), vibrational spectroscopy (Infrared, Near-infrared, Raman), mass spectroscopy (MS), nuclear magnetic resonance (NMR) spectroscopy, etc. [7][18].

The Republic of Rwanda is not spared from trafficking of poor quality medicines. Its government, highly aware of this situation, is continuously taking appropriate actions whenever feasible. For example, the regulatory system and analytical control laboratories are being implemented as well as the establishment of an AntiCounterfeit Products and Illicit Pharmaceuticals Unit in the Rwanda National Police under the Department of Interpol [19] [20]. As a contribution to this endeavor, the aim of this study was to describe a strategic approach to detect poor quality medicines, identify unknown components, and as much as possible to timely communicate alerts to the competent organizations such as the National Medicine Regulatory Authorities (NMRAs), Ministry of Health (MoH), Healthcare Non-Governmental Organizations (NGOs), Manufacturers, Distributors, Health centres, and the WHO. For that purpose, several analytical techniques including simple and complex methods were involved targeting antimalarial medicines.

Figure 1 depicts a step-by-step guide to accomplishing drug quality assessment from sampling to instrumental analysis. The main steps are sampling, visual inspection, laboratory preparedness, sample preparation, reporting the results, and timely alerts for appropriate measures against the use of detected poor quality products. After alerting, there is a need to conduct advanced analysis with powerful analytical techniques in order to identify the nature and extent of the defective situation in the studied products especially in case of counterfeiting.

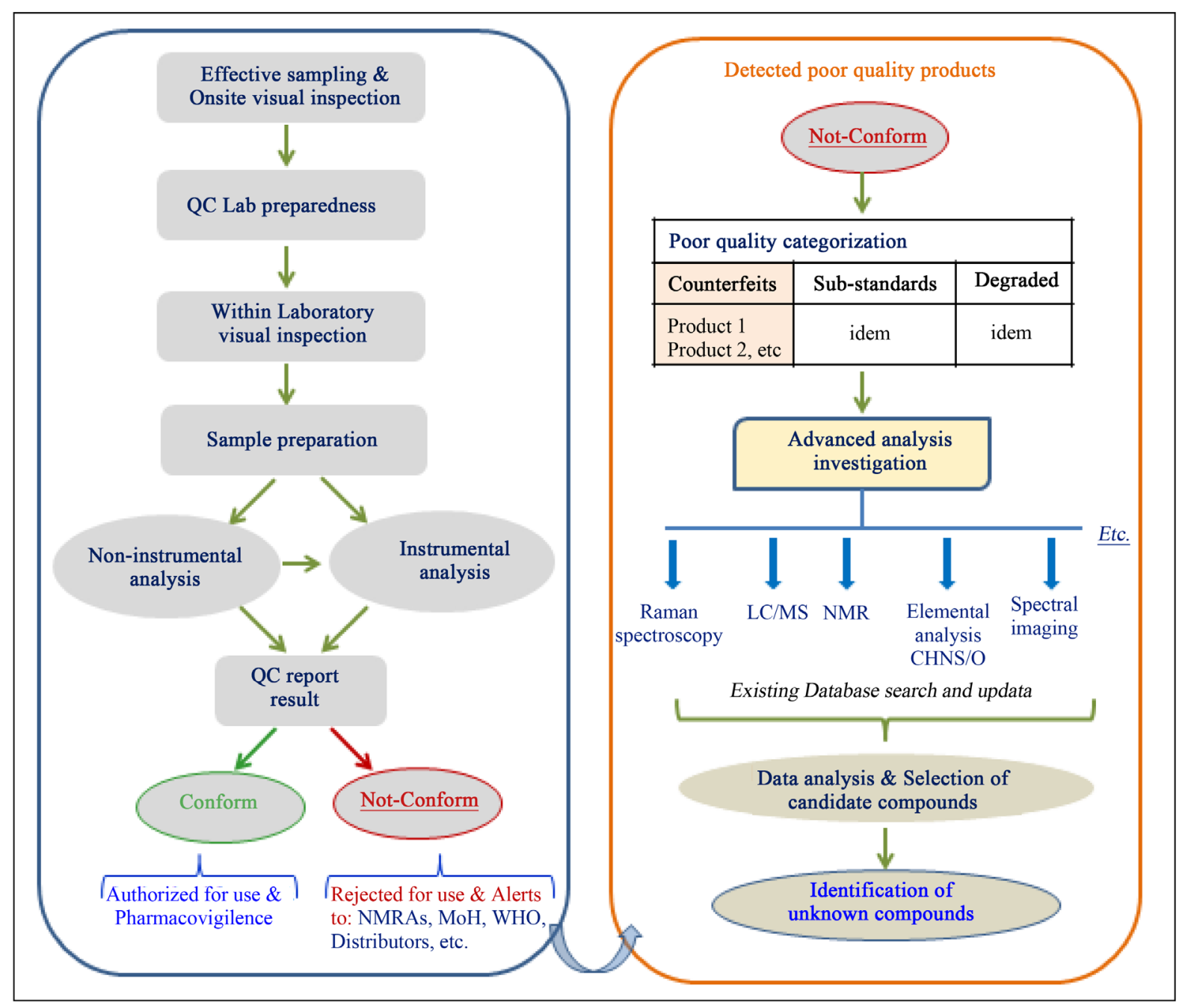

Figure 1. Step-by-step guide to drug quality control processing and alerting. 


\section{Materials and Methods}

\subsection{Drug Sampling}

As sampling sites, we privileged the countryside areas having intensive commercial activities due to border exchanges with Rwanda and neighboring countries namely, Burundi, Tanzania, Uganda, and D.R. Congo, and from which deceitful medicines could be infiltrated. For this study, we selected quinine and artemisinin-based preparations as most widely used antimalarial medicines in Rwanda. Different samples of quinine tablets 300 $\mathrm{mg}$, artemether-lumefantrine tablets $20 \mathrm{mg} / 120 \mathrm{mg}$, and artesunate powder for injection $60 \mathrm{mg}$ were randomly purchased in retail pharmacies or received free of charges from public institutions operating in the selected areas. They were submitted to visual inspection and instrumental analyses.

\subsection{Visual Inspection}

According to the WHO guidelines [2], we focused on differences in packaging, labeling, and physical appearance of the dosage forms characterized by specific size, shape and color in order to identify potential counterfeiting or deterioration. Suspected samples were further submitted to instrumental analysis to identify non-visual quality issues such as the presence of undeclared active ingredients or excipients, impurities and related contents.

\subsection{Instrumental Analysis Methods}

\subsubsection{Reagents and Solutions}

1) Reagents

Quinine sulfate (99.0\%) and metronidazole (99.9\%) reference substances were purchased from Fagron NV (Waregem, Belgium); Methanol LC grade from Avantor Performance Materials BV (Deventer, The Netherlands); hydrochloric acid (37\%) and Ammonium formate (98.1\%) from VWR International BVBA (Leuven, Belgium); Ultrapure water produced with Milli-Q Plus 185 water purification system (Millipore, Billerica, MA, USA); Dimethylsulfoxide "DMSO-d6" from Bruker (Billerica, MA, USA); Acetanilide and Sulfanilamide standards from ThermoQuest Italia S.p.A (Milan, Italy); Helium 6.0 ( $\geq 99.9999$ Vol\%) and Oxygen 4.5 ( $\geq 99.995$ Vol\%) from Alphagaz (Liège, Belgium).

2) Sample solutions for HPLC analysis

The test sample solutions for quinine tablets were prepared by dissolving in methanol LC grade accurately weighed quantities of the powders obtained from 20 tablets of each sample. Several dilutions were done to make final solutions equivalent to $100 \mu \mathrm{g} / \mathrm{mL}$ of quinine as analyte. The reference solutions were prepared in the same way to obtain the targeted $100 \mu \mathrm{g} / \mathrm{mL}$ concentration of the quinine. Two independent reference substances and three independent test sample solutions were prepared for the system suitability testing (SST) and for assay test. On the other hand, metronidazole was involved in the analysis as a wrong active ingredient in quinine tablets, and preparation of the standard and assay test solutions was done as following:

Standard preparation: Dissolve in methanol LC grade an accurately weighed quantity of metronidazole CRS to obtain $200 \mu \mathrm{g} / \mathrm{mL}$, and dilute half with the mixture water/methanol (80:20, v/v) to obtain a final standard solution of about $100 \mu \mathrm{g} / \mathrm{mL}$. Two independent reference solutions were prepared.

Assay preparation: Dissolve in methanol LC grade a quantity equivalent to about the average weight of one tablet from 20 single dose units finely powdered; make appropriate dilutions in methanol to obtain about 200 $\mu \mathrm{g} / \mathrm{mL}$ assuming that one tablet may contain $200 \mathrm{mg}$ of metronidazole, filter each solution on a microporous membrane (preferably $0.45 \mu \mathrm{m}$ pore size or less) and dilute as done for the standard solutions to have about 100 $\mu \mathrm{g} / \mathrm{mL}$ of metronidazole.

3) Sample solutions for UV-Visible spectroscopic analysis

A fast UV identification test using a spectrophotometer was done on the following solutions:

Quinine sulfate reference solutions at $50 \mu \mathrm{g} / \mathrm{mL}$ and $100 \mu \mathrm{g} / \mathrm{mL}$ : Dissolve in methanol LC grade a quantity of quinine sulfate CRS in order to obtain approximately $200 \mu \mathrm{g} / \mathrm{mL}$ of stock solution. Then, make appropriate dilutions with water to obtain 50 and $100 \mu \mathrm{g} / \mathrm{mL}$ solutions.

Test sample solutions at $50 \mu \mathrm{g} / \mathrm{mL}$ and $100 \mu \mathrm{g} / \mathrm{mL}$ : Dissolve in methanol LC grade a portion of fine powdered quinine tablets in order to obtain a stock solution containing $200 \mu \mathrm{g} / \mathrm{mL}$ of quinine sulfate active ingredient. Then, make appropriate dilutions with water to obtain expected concentrations of $50 \mu \mathrm{g} / \mathrm{mL}$ and 100 
$\mu \mathrm{g} / \mathrm{mL}$ solutions.

Metronidazole reference solutions at $50 \mu \mathrm{g} / \mathrm{mL}$ and $100 \mu \mathrm{g} / \mathrm{mL}$ : Use metronidazole CRS and prepare as per quinine sulfate reference solutions.

Blank solutions: Prepare mixtures of methanol-water at two proportion levels $(25: 75, \mathrm{v} / \mathrm{v})$ and $(50: 50, \mathrm{v} / \mathrm{v})$ to simulate the blank conditions at $50 \mu \mathrm{g} / \mathrm{mL}$ and $100 \mu \mathrm{g} / \mathrm{mL}$ respectively.

\subsubsection{HPLC Method}

The analyses by HPLC were carried out on a Waters 2695 Alliance (Waters, Milford, MA, USA) separation module coupled to Waters 2996 photodiode array (PDA) detector (Waters) applying an in-house developed method for quinine analysis and a USP procedure for metronidazole in tablets as described below. The system is controlled with Empower 2.0 software (Waters).

1) HPLC operating conditions for quinine analysis as developed in-house

For quinine analysis, the chromatographic separation was done in a Zorbax SB-C8 (dp $3.5 \mu \mathrm{m})$ column (150 $\mathrm{mm} \times 4.6 \mathrm{~mm}$ ID) maintained in a compartment thermostatted at $35^{\circ} \mathrm{C}$, applying as mobile phase a isocratic mixture of methanol and $10 \mathrm{mM}$ ammonium formate buffer adjusted to $\mathrm{pH} 2.5$ with $6 \mathrm{~N}$ hydrochloric acid (40:60, v/v) that was pumped at $1 \mathrm{~mL} / \mathrm{min}$. The sample solutions, thermostatted at $15^{\circ} \mathrm{C}$ in a compartment, were introduced onto the separation system at a rate of $10 \mu \mathrm{L}$ and monitored under the UV detection fixed at $230 \mathrm{~nm}$.

2) HPLC operating conditions for metronidazole assay as wrong active ingredient in quinine tablets

For metronidazole analysis, chromatographic separation was done also with Zorbax SB-C8 $(150 \mathrm{~mm} \times 4.6$ mm ID, dp: $3.5 \mu \mathrm{m}$ ) column in isocratic conditions, but using as mobile phase a mixture of methanol and water $(80: 20, v / v)$. Flow rate, injection volume and UV detection were maintained identical as for quinine except thermostatted sample and column compartments that were set at $15^{\circ} \mathrm{C}$ and $25^{\circ} \mathrm{C}$, respectively.

\subsubsection{Raman Spectroscopy Method}

Intact sample tablets vs. intact small quantities of reference materials were used. The samples were analyzed with LabRAM HR Evolution (Horiba scientific, Kyoto, Japan) instrument equipped with two-dimensional Newton 970 front-illuminated EMCCD detector $(1600 \times 200$ pixel sensor) (Andor Technology Ltd.), Leica 50× Fluotar LWD objective and $785 \mathrm{~nm}$ laser with a power of $45 \mathrm{~mW}$ (XTRA II single frequency diode laser, Toptica Photonics AG). A $300 \mathrm{gr} / \mathrm{mm}$ grating was used to record the spectra in the spectral range of $3200-100 \mathrm{~cm}^{-1}$. The confocal slit-hole was fixed at $200 \mu \mathrm{m}$. Each spectrum results of two acquisitions of 1 second. The spectra were collected with the LabSpec 6 (Horiba Scientific) software. Once acquired, the spectra were baseline corrected using the Asymmetric Least Squares (AsLS) algorithm with a $\lambda$ value of $10^{5}$ and a p-value of $10^{-3}$. The baseline corrected spectra were then scaled between 1 and 0 and compared to the spectral database. All spectrum processing and correlation coefficient computations were performed using Matlab R2013a software (The Matworks, Natick, MA, USA) and in-house routine coding.

\subsubsection{Mass Spectroscopy (ESI-MS)}

Four different solutions of the powdered fake quinine tablets (two samples), quinine sulfate and metronidazole references were prepared at $10 \mu \mathrm{g} / \mathrm{mL}$ in a mixture of methanol and water $(90: 10, \mathrm{~V} / \mathrm{V})$, and analyzed by direct injection in the ES+/MS analytical conditions hereafter described.

The mass spectrometry on a triple quadripole instrument from Waters Corporation (Milford, MA, USA) was used in a positive electrospray ionization mode (ES+), in MS and MS/MS modes. MassLynx 4.1 software (Waters Corporation) was selected for instrument control, data acquisition and handling. ES+/MS analytical conditions were set at Capillary Voltage $2.5 \mathrm{kV}$, dessolvation temperature $200^{\circ} \mathrm{C}$, Source Temperature $115^{\circ} \mathrm{C}$, Multiplier $650 \mathrm{~V}$.

\subsubsection{Nuclear Magnetic Resonance (NMR) Spectroscopy}

The ${ }^{1} \mathrm{H}$ NMR spectra were measured on a Bruker Avance (500 MHz) spectrometer (Wissembourg, France) equipped with a $5 \mathrm{~mm}$ TCI cryoprobe. Tetramethylsilane (TMS) was used as an internal standard. Chemical shifts were reported in $\delta$ values (ppm) relative to internal TMS. The abbreviation $\mathrm{s}=$ singlet, $\mathrm{d}=$ doublet, $\mathrm{t}=$ triplet, $\mathrm{m}=$ multiplet and $\mathrm{b}=$ broad were used throughout, and data were processed using Topspin 2.1 software (Bruker, Wissembourg, France).

The reference solutions of quinine sulfate and metronidazole were prepared by dissolving $2 \mathrm{mg}$ of the com- 
pound or equivalent of $2 \mathrm{mg}$ for quinine powdered tablets in $700 \mu \mathrm{l}$ of DMSO-d6 and then introduced into a 5 mm tube for analysis.

\subsubsection{Elemental Analysis (CHNS)}

Elemental analysis CHNS was also used to determine the percent weight of specific atoms of carbon (C), hydrogen $(\mathrm{H})$, nitrogen $(\mathrm{N})$ and sulfur $(\mathrm{S})$ in the suspected organic compounds, and therefore enabling to verify their empirical formula $\left(\mathrm{C}_{\mathrm{x}} \mathrm{H}_{\mathrm{y}} \mathrm{N}_{\mathrm{j}} \mathrm{S}_{\mathrm{k}}\right)$.

In this study, elemental analysis (CHNS) was realized on a Thermo Electron Corporation Flash EA 1112 CHNS Elemental Analyzer (Intersciencesprl, Louvain-la-Neuve, Belgium) equipped with a dry sample autosampler on the top of furnace, and under Eager 300 dedicated software control for organic elemental analysis in the following analytical conditions: $900^{\circ} \mathrm{C}$ for sample combustion, $130 \mathrm{~mL} / \mathrm{min}$ of the Carrier Flow, $100 \mathrm{~mL} /$ min for Reference Flow, $250 \mathrm{~mL} / \mathrm{min}$ for Oxygen Flow, $5 \mathrm{sec}$ for Oxygen Injection End $(0 \mathrm{sec}$ for Oxygen analysis), $12 \mathrm{sec}$ for Sample Delay Time, 10 min for Run time, and 2 - 3 mg for Sample weight.

\subsubsection{UV-Vis Spectroscopy}

A UV spectrophotometric analysis was done using a CECIL, CE 2501 model (2000 series) spectrophotometer (Cecil Instruments Limited, Milton Technical Centre, Cambridge, UK) by recording and comparing the reference and sample test solutions' absorption spectra acquired in the range between 200 and $400 \mathrm{~nm}$.

\section{Results}

\subsection{Visual Inspection Findings}

The pictures in Figure 2 and Figure 3 elucidate several cases of default and suspicious information confirming the usefulness of visual inspection at first line in decision making on drug quality when the product's physical appearance presents evident deviations to the quality standards. Indeed, various cases of poor quality medicines were detected such as the presence of discolored film coated quinine tablets, the packaging of artesunate powder for injection in different size boxes, the unlike batch numbers of artesunate powder for injection vials and outer packaging boxes, the fake packaging of artemether-lumefantrine blister tablets labelled COMBIART (Strides Arcolab Ltd) in LUMARTEM boxes (Quality Chemical Industries Ltd.), and infiltrated artemisinine-based combination therapy drug (ACT) from Uganda to Rwanda with a specific marginal note stating "Government of Uganda, For Public Use Only, Not for Sale". Note that the declared quinine tablets samples manufactured and/or distributed by HOLDEN MEDICAL (WEZEP-THE NETHERLANDS), HOLDEN MEDICAL (LELYSTAD-THE NETHERLANDS), and ELYS CHEMICALS (NAIROBI-KENYA) seemed to be visually normal. After these findings, the analyses continued following the step-by-step guide of Figure 1.

\subsection{General Pharmacopeial Tests}

As simple analytical tests, the following were processed: uniformity of mass, friability, disintegration, identification and assay according to the International Pharmacopoeia ( $4^{\text {th }}$ edition 2014) and United States Pharmacopoeia (USP 37-NF 32). The friability and disintegration tests results were within the specifications, but not the uniformity of mass for two particular samples manufactured and/or distributed by HOLDEN MEDICAL (WEZEPTHE NETHERLANDS), and ELYS CHEMICALS (NAIROBI-KENYA) illustrated in Appendix (Figure A1 and Figure A3). The mass of the product supposed to be manufactured and/or distributed by HOLDEN MEDICAL (WEZEP-THE NETHERLANDS) was $292.4 \pm 9.1 \mathrm{mg}$ (average and standard deviation, $\mathrm{n}=20$ tablets). The second quinine sample said (but not verified) to be manufactured by ELYS CHEMICALS (NAIROBIKENYA) was found with similar average mass of $297.6 \pm 6.1 \mathrm{mg}$ per tablet ( $\mathrm{n}=20$ tablets). These results were surprising and not coherent since the two samples were declared to contain $300 \mathrm{mg}$ of quinine sulfate. Hence, one can worry about the content of the active ingredient if the average weight is less than the declared content per tablet regardless the amount of excipients. Then, we decided on the basis of sampling periods and the incoherence of weight, to study and present these suspicious samples into two cases, one on underweight quinine tablets labelled HOLDEN MEDICAL (WEZEP-THE NETHERLANDS) and ELYS CHEMICALS (NAIROBIKENYA), and another on the normal weight tablets of quinine labelled HOLDEN MEDICAL (LELYSTADTHE NETHERLANDS). 


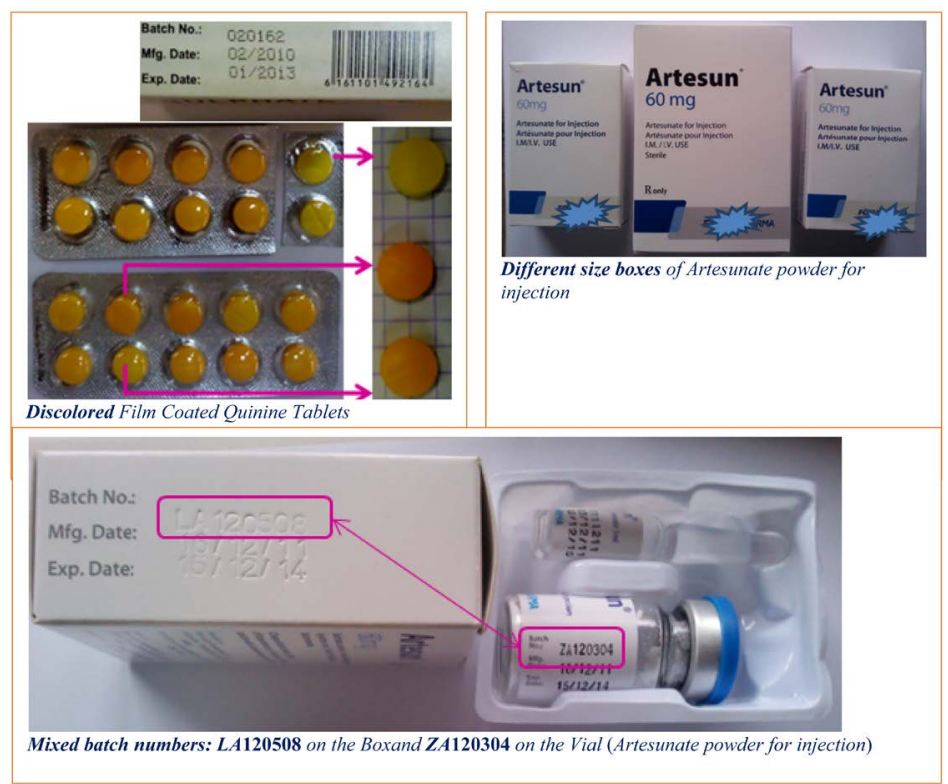

Figure 2. Photographs of poor quality quinine tablets and artesunate powder for injection.

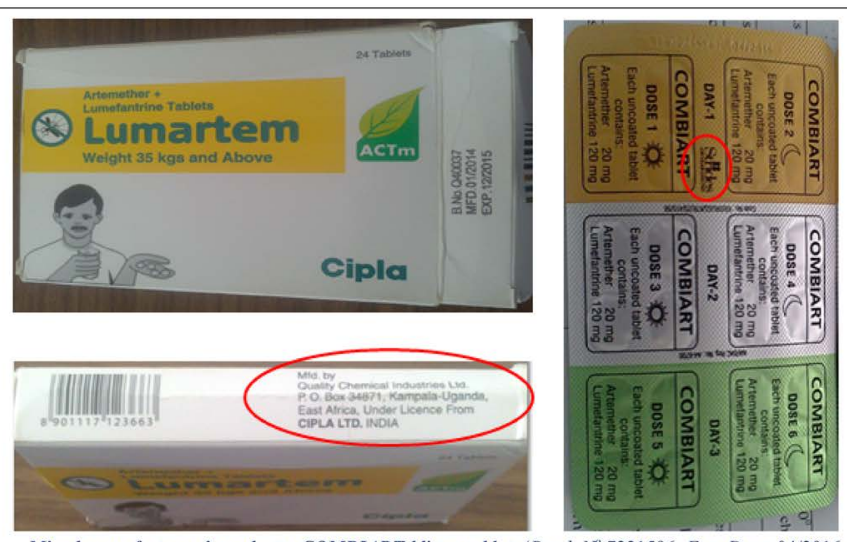

Mixed manufacturers' products: COMBIART blister tablets (Batch No 7221596, Exp. Date: 04/2016, Mfg. by Strides Arcolab Limited / country not specified), registered in Nigeria under NAFDAC Reg. No: A4-6700; LUMARTEM boxes (Batch No Q40037, Mfg. Date: 01/2014, Exp. Date: 12/2015, Mfg. by Quality Chemical Industries Ltd. Kampala-Uganda)
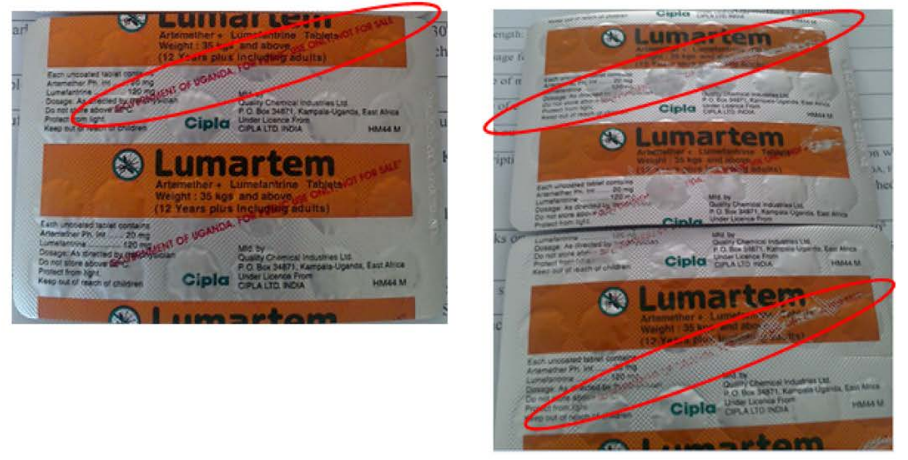

Infiltrated ACT medicine with a Specific Marginal Note stating: "GOVERNMENT OF UGANDA, FOR PUBLIC USE ONLY, NOT FOR SALE" Mfg. by Quality Chemical Industries Ltd. Kampala-Uganda) purchased in Rwanda. The second picture shows a sample of the same product but with intentional scratched marginal note to deceive the vigilance of consumers or inspectors.

Figure 3. Photographs of Artemether-Lumefantrine combination medicine illicitly introduced to Rwanda. 


\subsection{First Case}

\subsubsection{Fluorescence Analysis}

As a rapid identification test in the laboratory, we performed a visual observation of quinine fluorescence in both reference and sample solutions under UV light at $366 \mathrm{~nm}$. It clearly showed noticeable difference between quinine sulfate reference at $10 \mu \mathrm{g} / \mathrm{mL}$ that was greenish-blue color fluorescence whereas the suspected sample solutions at the same concentration level did not present any fluorescence (Figure 4).

\subsubsection{HPLC Analysis}

To explore the suspicious and illogical situation noticed above (Section 3.3.1), we carried out the most used separative technique in pharmaceutical analysis, namely HPLC. As shown on the chromatograms in Figure 5, the

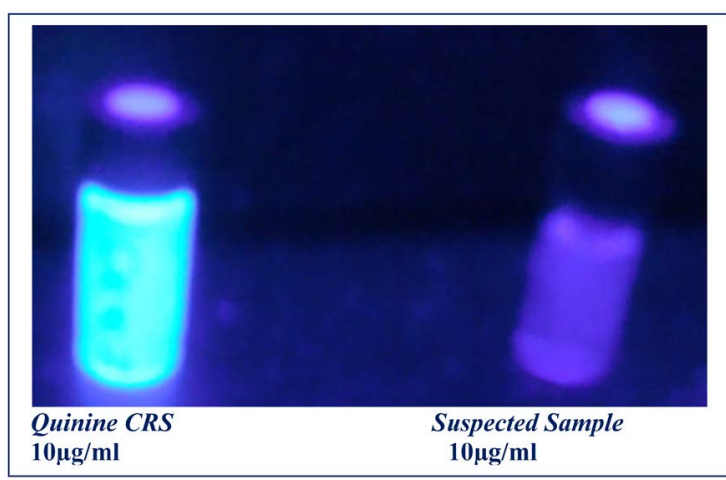

Figure 4. Quinine identification under UV light at $366 \mathrm{~nm}$ for fluorescence.
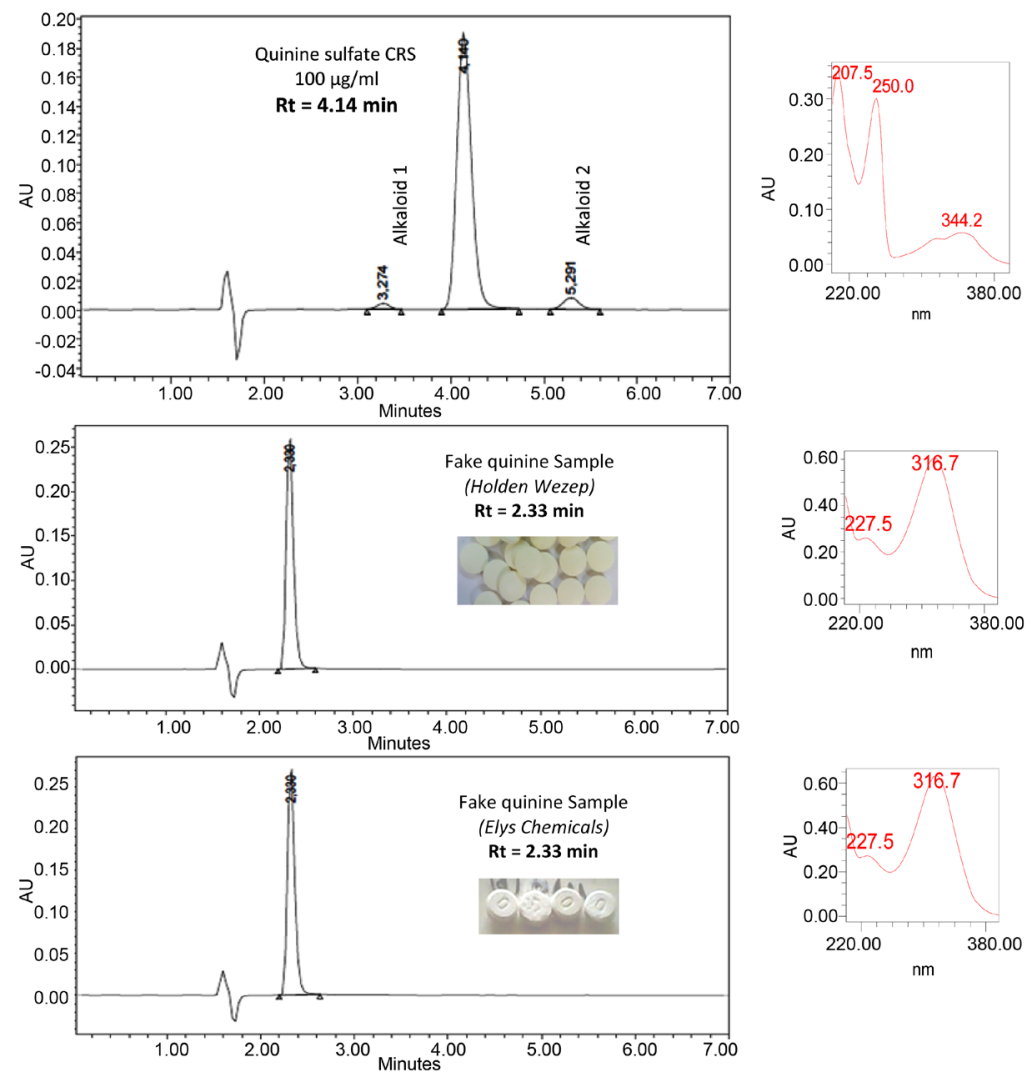

Figure 5. HPLC chromatograms and UV spectra of quinine sulfate CRS vs. fake samples. 
retention time of the major peak in the suspected false quinine tablets' solutions was 2.33 minutes, while the one of quinine reference substance eluted at 4.14 minutes. In addition, the analytical method was able to reveal two distinctive cinchona alkaloids at low concentrations generally present with quinine raw material or reference substance. The two alkaloids were identified cinchonidine and dihydroquinine eluting at 3.27 minutes and 5.29 minutes, respectively, and were not present in the suspected samples. Furthermore, the corresponding UV spectra extracted from PDA for the two suspected samples were totally different from the one for quinine reference substance (Figure 5), and the detected differences in terms of retention times and UV spectra were followed by further analytical investigation to identify the unknown component in the two samples.

\subsubsection{Raman Spectroscopy}

To pursue with the laboratory investigation, the Raman spectroscopic technique was used involving four basic steps to identify unknown components in the counterfeit products: 1) data acquisition on the studied samples, 2) instrument library search and update, 3) candidate products selection by fitting the experimental spectra to those in the database, and 4) identity confirmation of the unknown components by analyzing potential candidate substances vs. the samples.

The Raman spectra of the suspected quinine samples were found different from that of quinine sulfate reference substance. By comparing to Raman spectra database set up in the laboratory, it was noticed that the correlation coefficient corresponded very likely to metronidazole as potential candidate compound present in the suspected quinine tablets (cf. Table 1 and Figure 6 and Figure 7). Considering this new information, further analytical techniques were needed to confirm the identity of the unknown component.

Table 1. Raman spectrometry database search results for potential candidate products.

\begin{tabular}{|c|c|}
\hline Candidate product & Correlation coefficient \\
\hline Methylprednisolone & -0.064 \\
\hline Metronidazole & 0.996 \\
\hline Miconazole nitrate & -0.022 \\
\hline Microcristalline cellulose & 0.109 \\
\hline Naphazoline $\mathrm{HCl}$ & 0.161 \\
\hline Norfloxacine & 0.111 \\
\hline Noscapine $\mathrm{HCl}$ & -0.026 \\
\hline Oxazepam & -0.034 \\
\hline Paracetamol & 0.002 \\
\hline Paroxetine $\mathrm{HCl} .1 / 2 \mathrm{H}_{2} \mathrm{O}$ & 0.074 \\
\hline PEG 20000 & -0.074 \\
\hline Phenazone & -0.074 \\
\hline Phenoxymethylpenicilline K & -0.084 \\
\hline Phenylephrine $\mathrm{HCl}$ & -0.003 \\
\hline Pheniramine maleate & 0.139 \\
\hline Piperacillin $\mathrm{Na}$ & 0.038 \\
\hline Piperaquine & 0.390 \\
\hline Povidone & -0.022 \\
\hline Prednisolone & -0.045 \\
\hline Proguanil $\mathrm{HCl}$ & -0.015 \\
\hline Propranolol $\mathrm{HCl}$ & 0.265 \\
\hline Pseudoephedrine $\mathrm{HCl}$ & -0.012 \\
\hline Quinine $2 \mathrm{HCl}$ & 0.281 \\
\hline Quinine sulfate & 0.140 \\
\hline Saccharinate $\mathrm{Na}$ & -0.066 \\
\hline
\end{tabular}




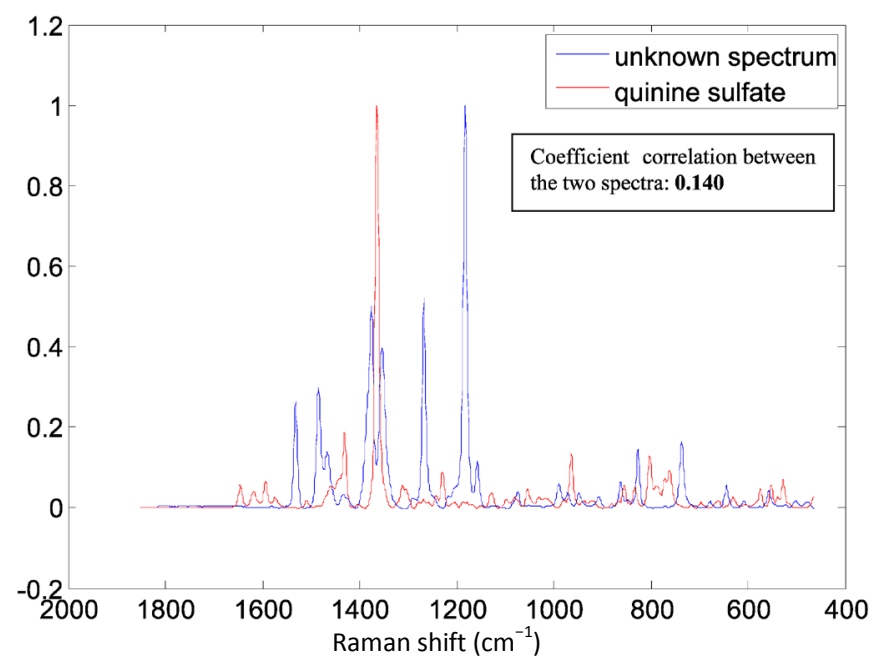

Figure 6. Raman spectra overlay for one of the two fake quinine tablets vs quinine sulfate CRS.

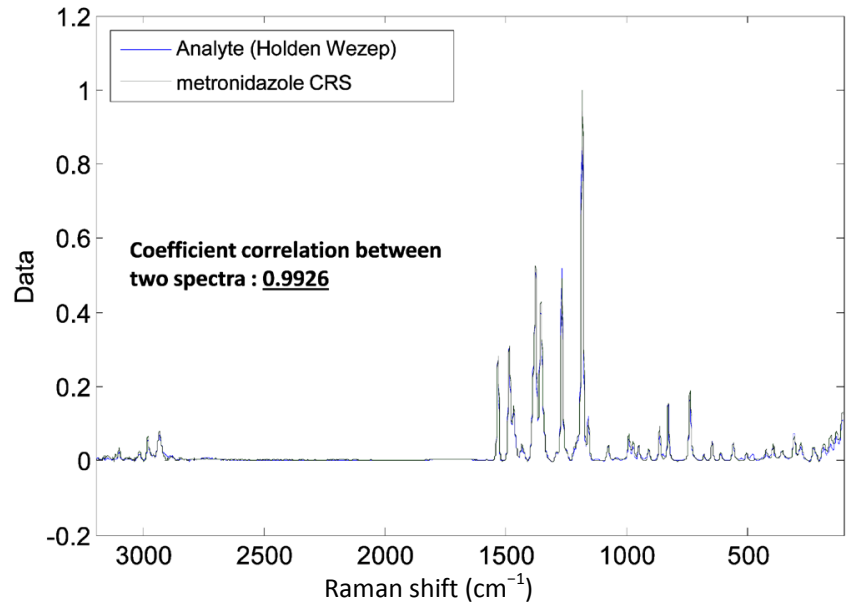

(a)

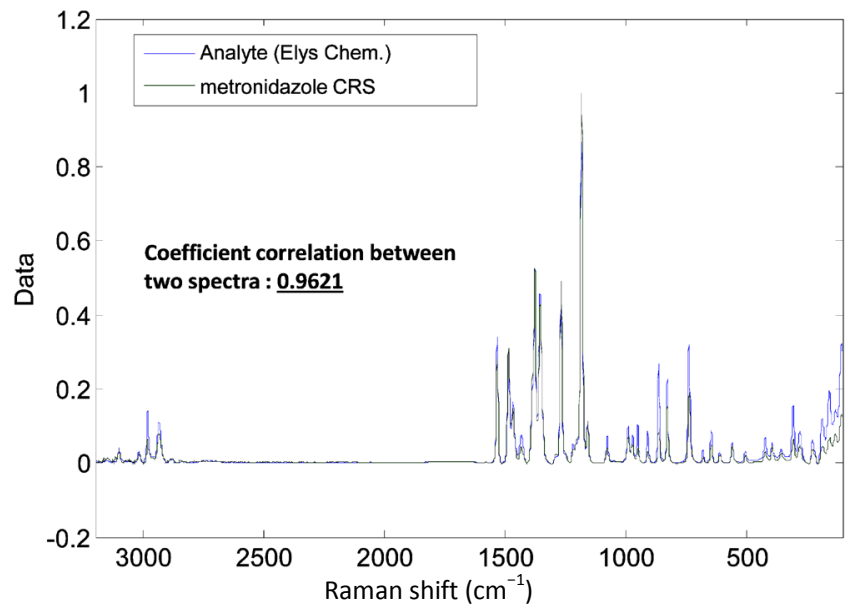

(b)

Figure 7. Raman spectra overlay for HOLDEN WEZEP and ELYS CHEMICALS fake quinine tablets vs metronidazole CRS (spectra overlay (a) and (b)). 


\subsubsection{Mass Spectrometry}

Both the MS and MS/MS were used. Their spectra presented in Figure 8 and Figure 9 confirmed the presence of metronidazole in the suspected quinine tablets. Indeed, the two samples have identical peaks with metronidazole reference substance, fragmentation profiles are very similar $(172>128,172>111)$ and relative abundance of the 128 and 111 peaks is the same in metronidazole CRS and in the two fake quinine samples.

\subsubsection{Nuclear Magnetic Resonance (NMR)}

By comparing respective ${ }^{1} \mathrm{H}$ NMR spectra, all signals of the "fake quinine tablets" exactly matched with the signals of metronidazole CRS but not with quinine sulfate (Figure 10), confirming again the presence of metronidazole in the suspected quinine tablets. Based on these previous analytical results (HPLC, Raman and MS), one can already confirm the absence of the declared active ingredient in the two samples.

\subsubsection{Elemental Analysis (CHNS)}

Finally, the contents in (\%) of carbon, hydrogen, nitrous and sulfur elements in the two samples were determined by elemental analysis. Considering $\pm 0.4 \%- \pm 0.5 \%$ for carbon and nitrous, $\pm 0.7 \%- \pm 0.8 \%$ for hydrogen, and $\pm 1 \%$ for sulfur as calculated acceptable error limits to each considered element, one can notice that the two fake quinine tablets have totally different results from that of quinine sulfate CRS as can be seen in Table 2 .

Indeed, the experimental \% values obtained for $\mathrm{N}, \mathrm{C}, \mathrm{H}$ and $\mathrm{S}$ in the suspected quinine samples (Holden Wezep,

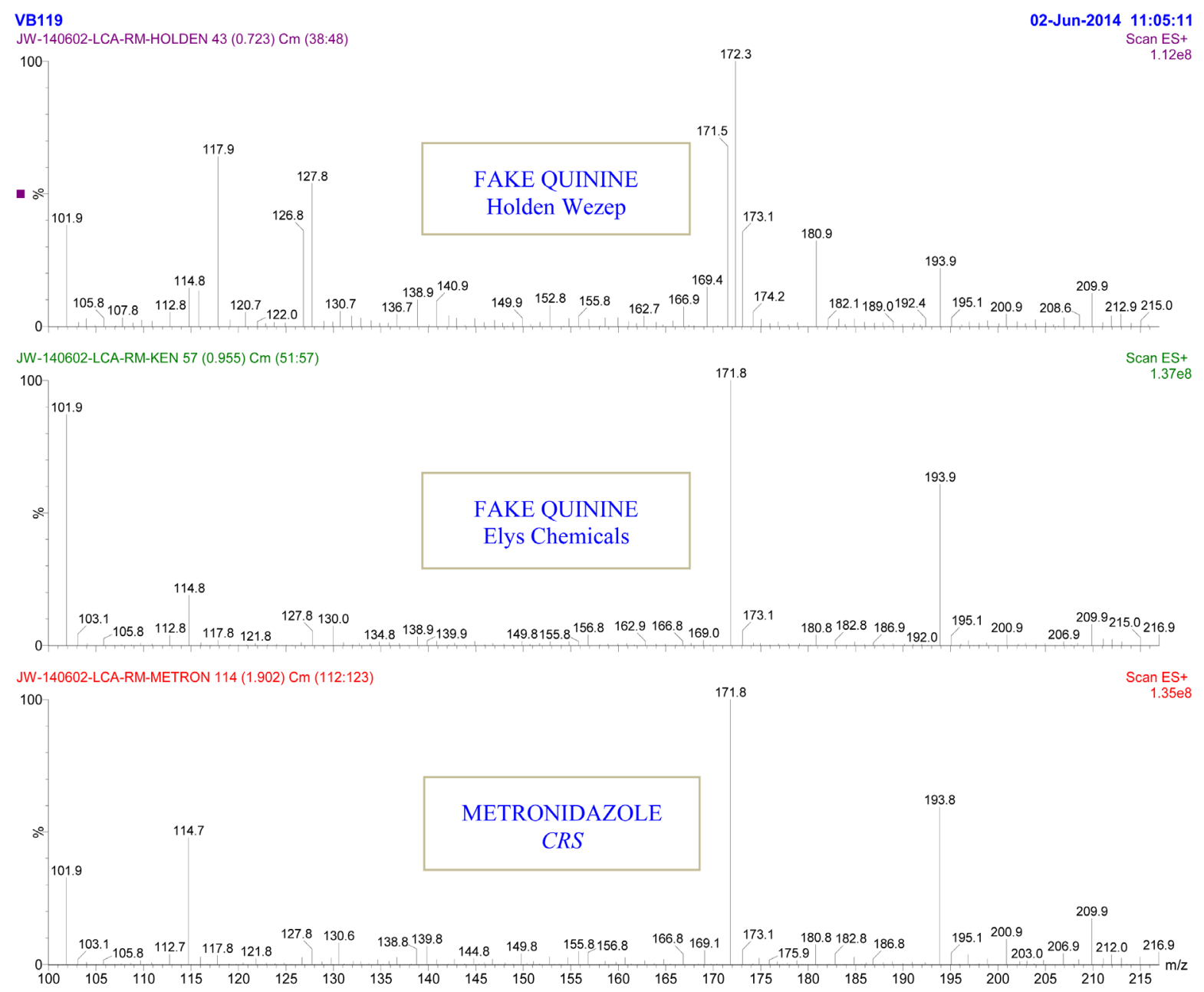

Figure 8. Comparison of ES+/MS spectra of metronidazole and the two fake quinine tablets (Elys chemicals and Holden Wezep) at 1.35e8, 1.37e8 and 1.12e8 Scan ES+ respectively. 


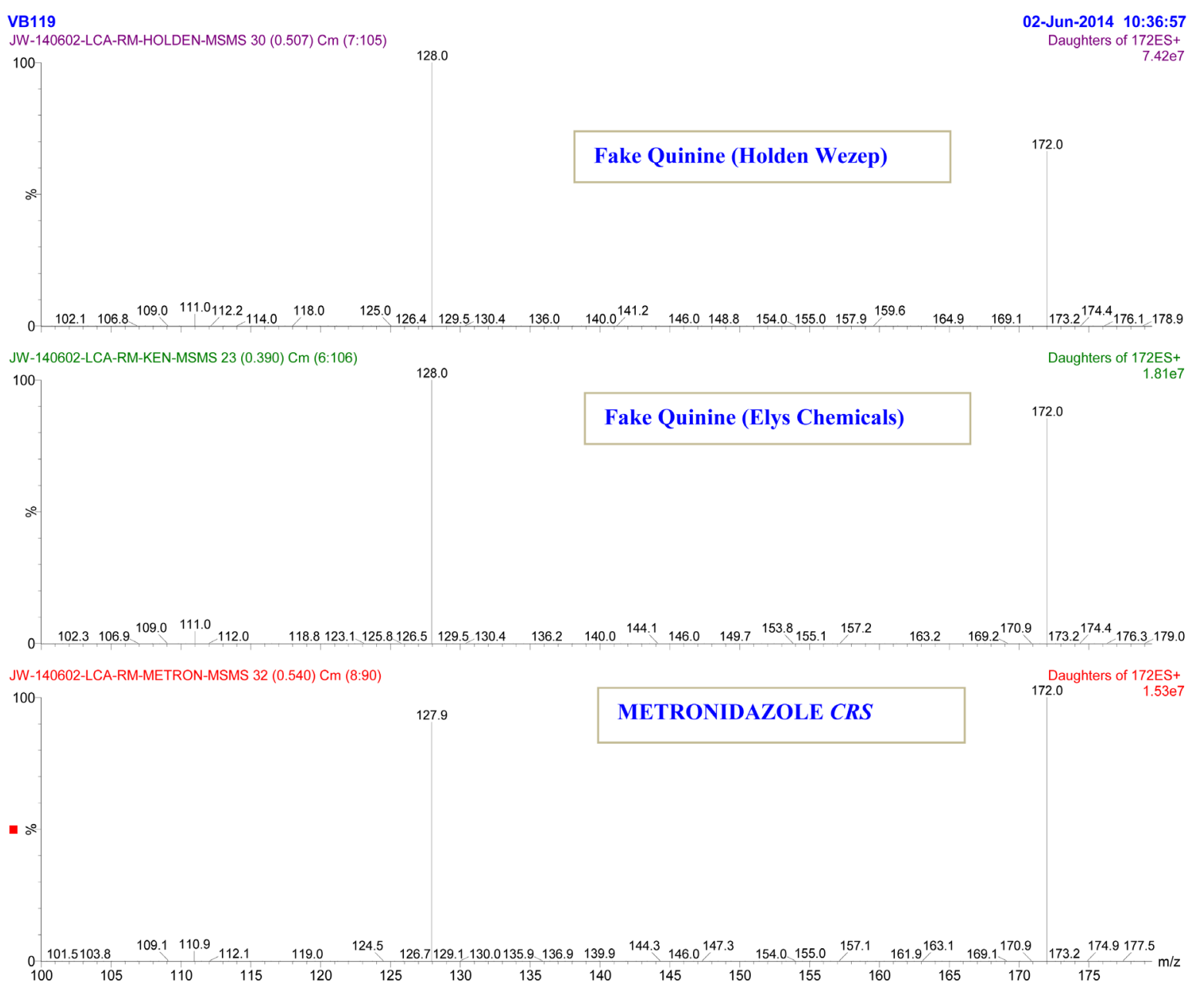

Figure 9. Comparison of ES+/MSMS daughters for metronidazole CRS, fake quinine (Elys chemicals) and Holden Wezep at $172 \mathrm{ES}^{+} 1.53 \mathrm{e} 7,172 \mathrm{ES}^{+} 1.81 \mathrm{e} 7$ and $172 \mathrm{ES}^{+}$7.42e7 respectively.

and Elys Chemicals) are very closer among themselves, and closer to the experimental \% values of metronidazole reference substance. However, they are particularly different from quinine sulfate for nitrous (about 3 times higher) and carbon (about 1.5 lower).

In addition, sulfur was not present in the two suspected and fake quinine samples. Such findings correspond more to metronidazole than to quinine sulfate. In fact, the absence of sulfur is not normal since quinine sulfate is used as raw material in the manufacture of quinine tablets and the sulfur content should be found in these samples.

\subsection{Assay Test Results of Metronidazole in the Two Fake Quinine Tablets}

After characterization and identification of the unknown component in the two fake quinine tablets, we decided to determine the content of metronidazole in the two particular formulations. We used an adapted analytical method to the USP-37/NF-32 (2014) as described in Materials and Methods. The content of metronidazole in the first sample (HOLDEN MEDICAL, WEZEP-THE NETHERLANDS) was found 81.6\%, and in the second sample 81.0\% (labeled ELYS CHEMICALS NAIROBI-KENYA).

\subsection{Second Case}

Another case of suspected quinine sulfate tablets was discovered one year later after the first study case. The sample was labelled HOLDEN MEDICAL (LELYSTAD-THE NETHERLANDS) and immediate suspicion on 


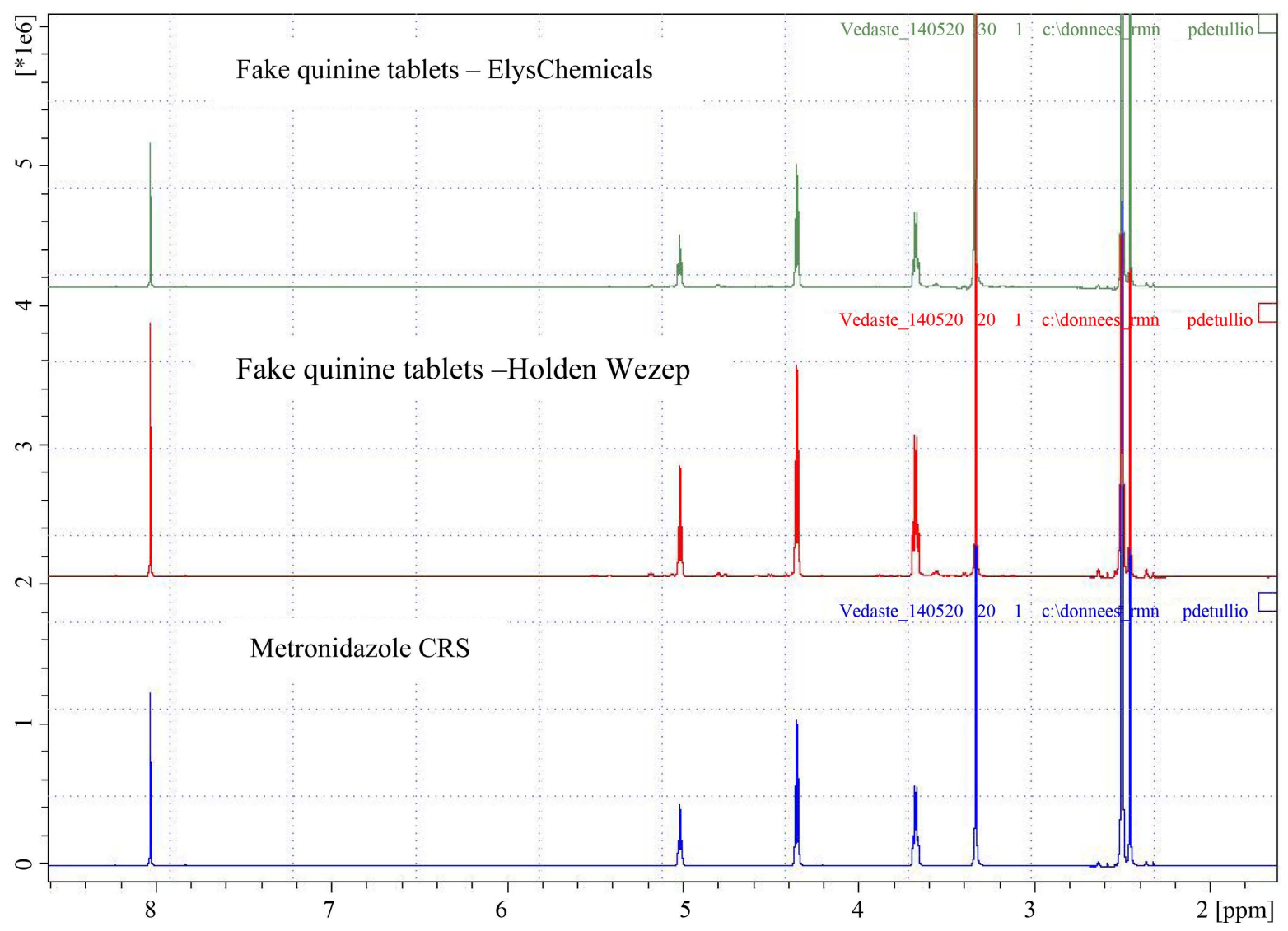

Figure 10. NMR spectra of fake quinine tablets and metronidazole reference substance.

Table 2. FlashEA 1112-CHN/S experimental results for metronidazole, quinine sulfate and fake quinine tablets.

\begin{tabular}{ccccccc}
\hline & \multicolumn{2}{c}{ Metronidazole CRS } & $\begin{array}{c}\text { Sample 1: } \\
\text { Holden Wezep }\end{array}$ & $\begin{array}{c}\text { Sample 2: } \\
\text { Elys Chemicals }\end{array}$ & Quinine sulfate CRS \\
\cline { 2 - 7 } Atom & $\begin{array}{c}\text { Theoritical } \\
(\%)\end{array}$ & $\begin{array}{c}\text { Experimental } \\
(\%)(\mathrm{n}=2) \\
\text { mean }\end{array}$ & $\begin{array}{c}\text { Experimental } \\
(\%)(\mathrm{n}=2) \\
\text { mean }\end{array}$ & $\begin{array}{c}\text { Experimental } \\
(\%)(\mathrm{n}=2) \\
\text { mean }\end{array}$ & $\begin{array}{c}\text { Theoritical } \\
(\%)\end{array}$ & $\begin{array}{c}\text { Experimental } \\
(\%)(\mathrm{n}=2) \\
\text { mean }\end{array}$ \\
\hline $\mathbf{N}$ & 24.55 & 25.14 & 22.21 & 20.59 & 7.16 & 7.67 \\
$\mathbf{C}$ & 42.1 & 42.11 & 46.00 & 41.85 & 61.36 & 60.89 \\
$\mathbf{H}$ & 5.3 & 5.38 & 5.77 & 5.49 & 6.95 & 6.98 \\
$\mathbf{S}$ & 0.0 & 0.0 & 0.0 & 0.0 & 4.1 & 3.4 \\
\hline
\end{tabular}

this product quality was mainly based on the fact that the name "HOLDEN MEDICAL (THE NETHERLANDS)" already known from the previous analysis on another sample of quinine sulfate tablets labelled HOLDEN MEDICAL (WEZEP-THE NETHERLANDS) found containing metronidazole as active ingredient. The two types of HOLDEN MEDICAL quinine tablets samples are illustrated in pictures given in Appendix (Figure A1 and Figure A2).

\subsubsection{Visual Inspection and General Pharmacopeial Tests}

Visual inspection and general pharmacopeial tests such as the uniformity of mass, friability and disintegration tests were processed as done in the first case analysis, but identification was done on a UV-Vis spectrophotometer to collect the UV spectra for comparison, and therefore confirm similarity with the first case. The assay test 
was not performed on this sample as the main purpose was to see if the product was also counterfeited with metronidazole as in the previous Holden sample despite their differences in shape, color, size and probably manufacturing sites (WEZEP-THE NETHERLANDS for the previous sample, and LELYSTAD-THE NETHERLANDS for the new sample). The new suspected quinine sulfate tablets $300 \mathrm{mg}$ average weight was found $426.5 \pm$ $3.6 \mathrm{mg}$ which is logical including the excipients content. The tests of friability and of disintegration complied with the pharmacopeial specifications.

\subsubsection{UV-Vis Spectroscopy}

This technique was used to rapidly identify the active ingredient in that sample by comparing its UV spectrum to those of metronidazole and quinine sulfate reference substances. The UV spectrum of the sample did not match with the spectrum of quinine reference solution, however and again surprisingly the sample UV spectrum matched very well with metronidazole reference standard solution. After confirming that the new sample labelled HOLDEN MEDICAL (LELYSTAD-THE NETHERLANDS) contains the same wrong ingredient as in the HOLDEN MEDICAL (WEZEP-THE NETHERLANDS) sample, we decided to not perform further analysis with advanced analytical techniques as done in the first case, because the relevant information on the nature of counterfeiting was already known.

\section{Discussion}

During this study, careful visual inspection has enabled to detect easily a series of poor quality antimalarial medicines such as the presence of 1 ) discolored film coated quinine tablets that may contain toxic substances, impurities and or sub-degradation substances. The discoloration should be a result of poor storage conditions and subsequent degradation, poor manufacturing or even counterfeiting; 2) Different sized boxes and mixed batch materials of artesunate powder for injection that may also be a result of drug counterfeiting or substandard manufacturing conditions; 3) Packed COMBIART blister tablets (Mfd. by Strides Arcolab Ltd) in LUMARTEM boxes (Mfd. by Quality Chemical Industries Ltd.) is clearly a result of drug counterfeiting because normally no official manufacturer should mix two different manufacturers' products; 4) Artemether-Lumefantrine combination tablets infiltrated to Rwanda with a marginal note stating "GOVERNMENT OF UGANDA, FOR PUBLIC USE ONLY, NOT FOR SALE” illegally introduced to Rwanda and sold. Another related quality issue to the later product, is that some illicit vendors tried to scratch the marginal note in order to cheat the vigilance of patients or inspectors.

On the other hand, laboratory testing had revealed surprising results on three different samples of tablets declared to contain quinine sulfate $300 \mathrm{mg}$ and labeled HOLDEN MEDICAL (WEZEP-THE NETHERLANDS), HOLDEN MEDICAL (LELYSTAD-THE NETHERLANDS) and ELYS CHEMICALS (NAIROBI-KENYA). Normally the average weight of tablets medicines is always greater than the declared content of active ingredient(s) due to the presence of excipients, however this was not the case for Holden Medical (Wezep-The Netherlands) and Elys Chemicals (Nairobi-Kenya) who have lower average weights than the declared active ingredient's amount. The identification test of quinine fluorescence under UV light had also failed on both samples, and further analysis with advanced analytical instruments such as HPLC, Raman spectroscopy, Mass spectroscopy, NMR and Elemental Analysis revealed that the two types of quinine tablets contain metronidazole instead of quinine. For Holden Medical (Lelystad-The Netherlands) quinine tablets samples of the second case, the average weight cannot cause suspicion to poor quality since it was higher than the declared active ingredient's amount. However, the UV spectrum has confirmed substitution of quinine sulfate by metronidazole. Something surprising is that the three fake quinine tablets despite their different shapes, color, and names (labelling) have the same wrong ingredient metronidazole which is an antimicrobial, antiprotozoal/anti-amoebic. On the other hand, this is very cunning from counterfeiters as metronidazole is relatively bitter like quinine, but more than ten times cheaper [21].

Quantitative analysis of metronidazole in HOLDEN MEDICAL (WEZEP-THE NETHERLANDS) and ELYS CHEMICALS (NAIROBI-KENYA) quinine tablets revealed that not only counterfeiters have used a wrong active ingredient, but also the products are under-doses. This may refer to thinking about falsification of the active ingredient during production or falsification during packaging and labelling. Hence, several public health consequences may be possible for consumers such as the failure in malaria treatment, development of drug resistance for plasmodium, increase of morbidity and mortality due to malaria, etc. 
After noticing that the products were counterfeit and therefore dangerous to the public health, immediate alerts were sent to the vendors, the Pharmacy Task Force of the Ministry of Health (Rwanda), and to the National Procurement and Distribution Center for appropriate measures against these products; but also for careful control of other medicines that would be circulating in the country from the same manufacturers or distributors.

Concerning the other antimalarial samples, even if visual inspection was not satisfying, the declared active ingredients were confirmed to be present at the expected and declared content. However, note that each medicine should comply with all required quality specifications for safe use.

From this study, one can notice how advanced analytical techniques such as HPLC, Raman spectroscopy, mass spectroscopy, NMR, and elemental analysis (CHNS) are complementary and efficient in the detection and characterization of unknown components in counterfeit medicines. One can also rely on the database of simple analytical technique such as the UV-Vis spectroscopy that was successfully used to detect the second case of suspected Holden quinine sample.

\section{Conclusion}

A strategic approach to detect poor quality medicines and identify unknown components in counterfeit antimalarial medicines has been applied in this study that allowed detection of several cases. Some of them were detected by means of simple and affordable tools such as visual inspection and tablets weighing, whereas in other cases it was necessary to exploit complex tools namely pharmacotechnique and analytical ones. The latter were applied for deep analyses in order to evaluate the quality of three quinine sulfate tablets samples that were found containing metronidazole instead of quinine. Timely alerts were sent to all concerned parties, medical and pharmaceutical, based on scientific evidences found for appropriate measures against the spread of the detected harmful products. In fine, the study results illustrated and highlighted the necessity to strengthen National Medicines Regulatory Authorities, especially in developing countries in order to ensure among other responsibilities that all distributed medicines are of the required quality, safety and efficacy.

\section{Acknowledgements}

Thanks to the Belgian Technical Cooperation (BTC/CTB) for scholarship and financial support to V. Habyalimana (award number 11RWA/0004).

\section{References}

[1] (2008) Sanofi-Aventis, Press Pack: Drug Counterfeiting. http://ec.europa.eu/internal market/indprop/docs/conf2008/wilfried roge en.pdf

[2] World Health Organization (WHO) (1999) Counterfeit Drugs: Guidelines for the Development for Measures to Combat Counterfeit Drugs. http://apps.who.int/medicinedocs/pdf/h1456e/h1456e.pdf

[3] World Health Organization (WHO) Fact Sheet Revised (2006) Essential Medicines and Health Products—Counterfeit Medicines. www.who.int/medicines/services/counterfeit/impact/ImpactF_S/en/

[4] The Financial Times by Joseph Milton (2012) Fake Medicines: Illegal, Immoral and Liable to Increase Drug Resistance. www.cmpi.org/in-the-news/in-the-news/fake-medicines-illegal-immoral-and-liable-to-increase-drug-resistance/

[5] Newton, P.N., Amin, A.A., Bird, C., Passmore, P., Dukes, G., et al. (2011) The Primacy of Public Health Considerations in Defining Poor Quality Medicines. PLoS Medicine, 8, e1001139.

http://dx.doi.org/10.1371/journal.pmed.1001139

[6] International Council of Nurses (ICN), United States Pharmacopoeia (USP), International Pharmaceutical Federation (FIP) (2014) Tool for Visual Inspection of Medicines. https://www.fip.org/files/fip/counterfeit/VisualInspection/A\%20tool\%20for\%20visual\%20inspection\%20of\%20medici nes\%20EN.pdf

[7] Deconinck, E., Sacré, P.Y., Courselle, P. and De Beer, J.O. (2013) Chromatography in the Detection and Characterization of Illegal Pharmaceutical Preparations. Journal of Chromatographic Science, 51, 791-806. http://dx.doi.org/10.1093/chromsci/bmt006

[8] Monge, M.E., Dwivedi, P., Zhou, M., Payne, M., Harris, C., et al. (2014) A Tiered Analytical Approach for Investigating Poor Quality Emergency Contraceptives. PLoS ONE, 9, e95353. http://dx.doi.org/10.1371/journal.pone.0095353

[9] Fernandez, F.M., Hostetler, D., Powell, K., Kaur, H., Green, M.D., Mildenhall, D.C. and Newton, P.N. (2011) Poor Quality Drugs: Grand Challenges in High Throughput Detection, Countrywide Sampling, and Forensics in Developing 
Countries. Analyst, 136, 3073-3082. http://dx.doi.org/10.1039/C0AN00627K

[10] Dégardin, K., Roggo, Y. and Margot, P. (2014) Understanding and Fighting the Medicine Counterfeit Market. Journal of Pharmaceutical and Biomedical Analysis, 87, 167-175. http://dx.doi.org/10.1016/j.jpba.2013.01.009

[11] Kaur, H., Green, M.D., Hostetler, D.M., Fernáández, F.M. and Newton, P.N. (2010) Antimalarial Drug Quality: Methods to Detect Suspect Drugs. Therapy, 7, 49-57. http://dx.doi.org/10.2217/thy.09.84

[12] Pathirana, C., Bolgar, M.S., Peddicord, M.B., Miller, A.S. and Shackman, M.H. (2014) Application of Mass Spectrometry to Support Verification and Characterization of Counterfeit Pharmaceuticals. LC-GC Special Issue on Currents Trends in Mass Spectrometry.

[13] Sacré, P.Y., Deconinck, E., De Beer, T., Courselle, P., Vancauwenberghe, R., Chiap, P., Crommen, J. and De Beer, J.O. (2010) Comparison and Combination of Spectroscopic Techniques for the Detection of Counterfeit Medicines. Journal of Pharmaceutical and Biomedical Analysis, 53, 445-453. http://dx.doi.org/10.1016/j.jpba.2010.05.012

[14] Roggo, Y., Degardin, K. and Margot, P. (2010) Identification of Pharmaceutical Tablets by Raman Spectroscopy and Chemometrics. Talanta, 81, 988-995. http://dx.doi.org/10.1016/j.talanta.2010.01.046

[15] Dégardin, K., Roggo, Y., Been, F. and Margot, P. (2011) Detection and Chemical Profiling of Medicine Counterfeits by Raman Spectroscopy and Chemometrics. Analytica Chimica Acta, 705, 334-341. http://dx.doi.org/10.1016/j.aca.2011.07.043

[16] Marini, R.D., Rozet, E., Montes, M.L., Rohrbasser, C., Roht, S., Rhème, D., Bonnabry, P., Schappler, J., Veuthey, J.L., Hubert, P. and Rudaz, S. (2010) Reliable Low-Cost Capillary Electrophoresis Device for Drug Quality Control and Counterfeit Medicines. Journal of Pharmaceutical and Biomedical Analysis, 53, 1278-1287. http://dx.doi.org/10.1016/i.jpba.2010.07.026

[17] Mustazza, C., Borioni, A., Rodomonte, A.L., Bartolomei, M., Antoniella, E., Di Martino, P., Valvo, L., Sestili, I., Costantini, E. and Gaudiano, M.C. (2014) Characterization of Sildenafil Analogs by MS/MS and NMR: A Guidance for Detection and Structure Elucidation of Phosphodiesterase-5 Inhibitors. Journal of Pharmaceutical and Biomedical Analysis, 96, 170-186. http://dx.doi.org/10.1016/j.jpba.2014.03.038

[18] Wiest, J., Schollmayer, C., Gresser, G. and Holzgrabe, U. (2014) Identification and Quantitation of the Ingredients in a Counterfeit Vietnamese Herbal Medicine against Rheumatic Diseases. Journal of Pharmaceutical and Biomedical Analysis, 97, 24-28. http://dx.doi.org/10.1016/j.jpba.2014.04.013

[19] Rwanda National Police News, RNP Committed to Fighting Illicit Pharmaceuticals-ACP Kuramba, 7 February 2015. http://www.police.gov.rw/news-detail/?tx ttnews[tt news]=3591\&cHash=ac2ccbcdf8f365d0b6d815206830a6aa

[20] International Institute of Research Against Counterfeit Medicines (IRACM), A Specialized Unit Is Focused on the Fight against Fake Drugs and Counterfeiting in Rwanda (Posted on 9 March 2015).

http://www.iracm.com/en/2015/03/a-specialized-unit-is-focused-on-the-fight-against-fake-drugs-and-counterfeiting-inrwanda/

[21] MSH/WHO, International Drug Price Indicator Guide, 2013.

http://apps.who.int/medicinedocs/documents/s21497en/s21497en.pdf 


\section{Appendix}

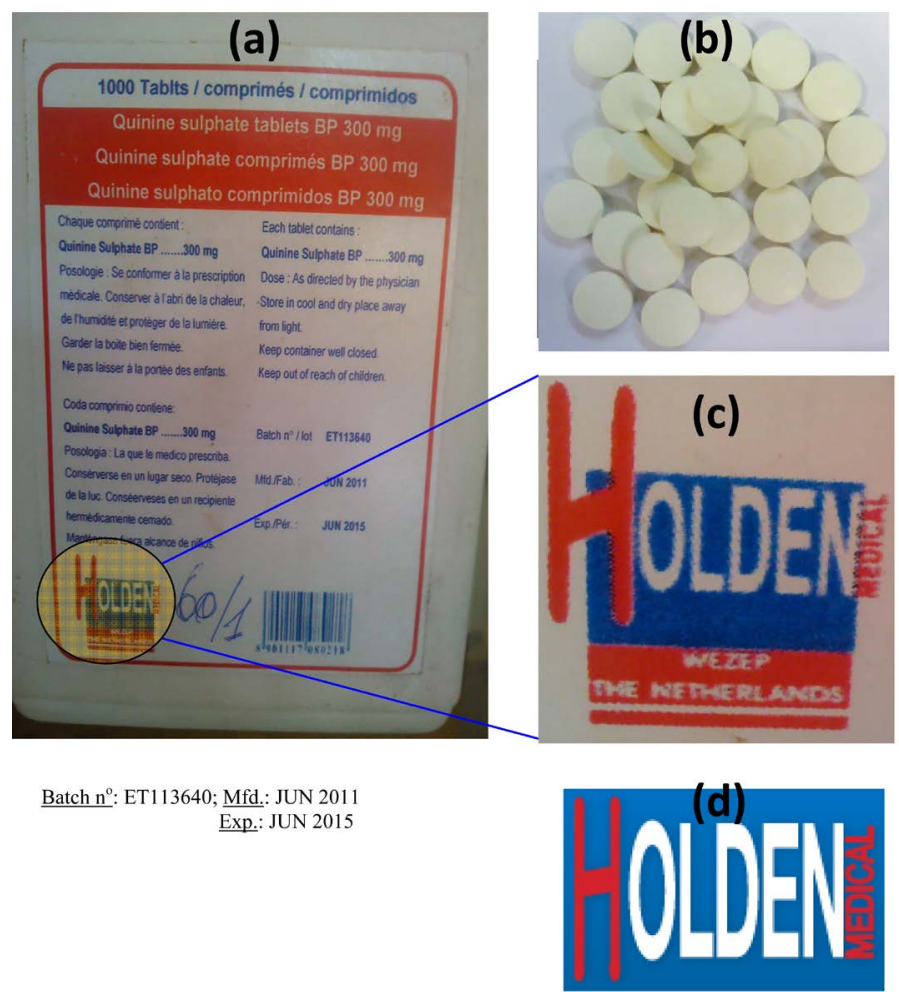

Figure A1. Picture of HOLDEN MEDICAL (WEZEP-THE NETHERLANDS) fake quinine sample. (a) Sample labeling information on a "cubical plastic box"; (b) Packed biconvex yellow tablets without a break line; (c) Logo of either the manufacturer or distributor (not specified!); (d) Logo of HOLDEN MEDICAL (picked from internet for comparison: http://www.holdenmedical.com/web/show/contact), last visited on Sept 12 $2^{\text {th }}, 2014$.

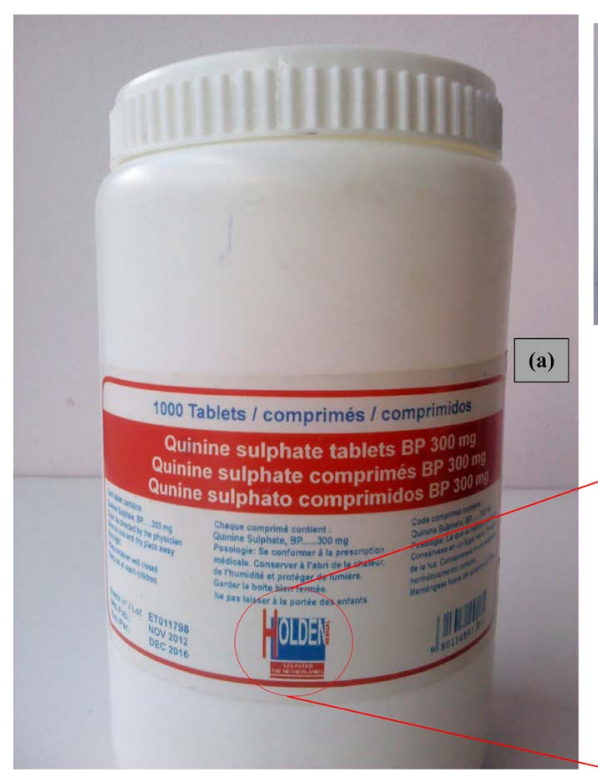

Batch n ${ }^{\circ}:$ ET011798; Mfd.: Nov 2012

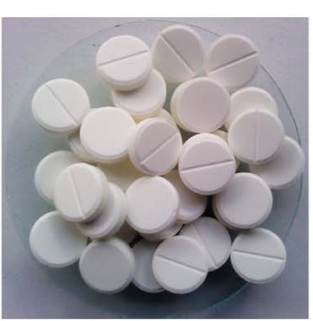

(b)

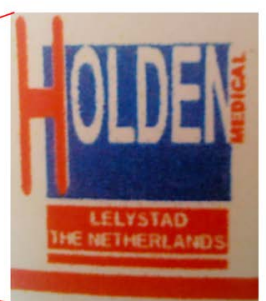

(c)

Figure A2. Picture of HOLDEN MEDICAL (LELYSTAD-THE NETHERLANDS) fake quinine tablets sample. (a) Sample labeling information on a "cylindrical plastic box"; (b) Packed white flat-faced bevel-edged bisect tablets; (c) Logo of either the manufacturer or distributor (not specified!). 


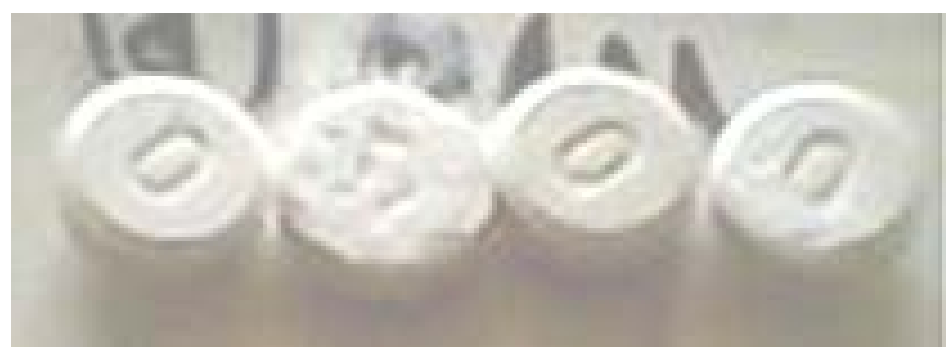

Figure A3. Picture of ELYS CHEMICALS (NAIROBI-KENYA) fake quinine tablets sample. Note: The picture was taken after the friability test. 